\title{
Lateral variation of the uppermost oceanic plate in the outer-rise region of the Northwest Pacific Ocean inferred from Po-to-s converted waves
}

\author{
Takashi Tonegawa* ${ }^{*}$, Koichiro Obana, Gou Fujie and Shuichi Kodaira
}

\begin{abstract}
The uppermost structures of incoming oceanic plates have been investigated by seismic exploration surveys, primarily based on two-dimensional profiles. However, their regional-scale lateral variations and shear wave velocity structures with higher-frequency components remain elusive. This study, using passive seismic records, attempted to retrieve Po-to-s converted waves (Pos) by cross-correlating Po wave coda from the radial and vertical components in the 2-6 Hz frequency band and to show lateral variations of the shear wave velocity within the oceanic crust, including crust-related seismic interfaces and layer-dependent anisotropic structures. Po waves were collected from continuous records acquired from active seismic surveys performed across wide areas of the Northwestern Pacific over shorter observation periods and passive seismic surveys performed near the Japan Trench over longer observation periods. As a result, this study obtained clear Pos waves converted at the basement and oceanic Moho of the seaward region, whereas weakened or no Pos waves were observed at ocean bottom seismometers near the trench. The primary reasons for Pos wave weakening or absence were considered to be structural changes, including normal faults due to the plate flexures in the outer-rise region, hydration at the uppermost oceanic plate, and fractures associated with volcanic activities that can be seen on the oceanic plate (petit spots). Furthermore, layer-dependent shear wave anisotropies were estimated for the sediment and crust. Fast polarization directions were oriented in trench-parallel directions near the trench and in the NNW-SSE directions in the seaward region. The pattern change to near-trench polarization directions would correspond to stress field-induced aligned fractures, including cracks and normal faults, created by stress fields induced by plate bending in the outer-rise region.
\end{abstract}

Keywords: Po wave, Incoming oceanic plate, Basement, Moho, Anisotropy

\section{Introduction}

The seismological characteristics of incoming oceanic plates in various subduction zones have been investigated by both active and passive seismic surveys (e.g., Ranero et al. 2003; Ranero and Sallarès 2004; Grevemeyer et al. 2007; Shinohara et al. 2008; Brillon et al. 2013; Fujie et al. 2013, 2016; Obana et al. 2012, 2013, 2014, 2018; Kodaira et al. 2014; Bécel et al. 2015; Shillington et al. 2015). Several active survey results have revealed seismic velocity

\footnotetext{
*Correspondence: tonegawa@jamstec.go.jp

Japan Agency for Marine-Earth Science and Technology (JAMSTEC),

3173-25, Showa-machi, Kanazawa-ku, Yokohama 236-0001, Japan
}

reductions at the uppermost oceanic plate near trenches (Ranero et al. 2003; Ranero and Sallarès 2004; Grevemeyer et al. 2007; Fujie et al. 2013; Shillington et al. 2015), which can be explained by fractures associated with plate bending in the outer-rise region (Faccenda et al. 2009). If pore water in such fractures and bound water in hydrous minerals are present in sufficient amounts in the crust and uppermost mantle, water may plausibly be transported to deep subduction zones, potentially controlling seismic activities at the plate interface (Shelly et al. 2006) and within the subducting slab (Hacker et al. 2003; Yamasaki and Seno, 2003; Kita et al. 2006; Eberhart-Phillips et al. 2013). In addition to seismic velocity, seismic 
anisotropy information is important for investigating fracture creation near trenches, as shear wave speeds increase when polarized into aligned fractures.

Active seismic surveys are useful for investigating the uppermost oceanic plate. Although most passive seafloor observations use teleseismic waves because part or all survey areas are distant from seismically active regions (e.g., Brillon et al. 2013), the high-frequency components of such waves are insufficient relative to those of active sources. If converted waves could be retrieved from passive seismic surveys at high frequencies, signals obtained from different approaches could be compared or interpreted.

This study attempted to detect $P o$-to-s converted waves (Pos) isolated from $P o$ wave propagating within the oceanic mantle. When $P$ and $S$ waves are excited by an earthquake occurring within the subducting slab, $P o$ and $S o$ waves are developed from the multiple scatterings of the $P$ and $S$ waves owing to small-scale stochastic random heterogeneities in the oceanic mantle (Shito et al. 2013). These waves propagate over distances up to $3000 \mathrm{~km}$ and often manifest long-duration, high-frequency $(>2 \mathrm{~Hz})$ recordings in the seafloor observation (Kennett and
Furumura, 2013; Shito et al. 2013, 2015). This study used Po waves observed in the northwestern part of the Pacific Plate (Fig. 1 and Additional file 1: Fig. S1). In this region, the Pacific Plate (ages 130-140 Ma) is moving in a westnorthwest direction with subducts from the Japan and Kuril Trenches. As Po waves are observed at the seafloor through refraction at the basement and inside or bottom (Moho) of the oceanic crust, Pos waves converted at these interfaces may also be observed (Fig. 2).

In this paper, the process of extracting Pos waves from Po wave coda and the estimation of anisotropic structures explained in detail in "Methods" section. "Results" section describes the retrieval of Pos waves converted at the basement and oceanic Moho, as well as the pattern of the fast polarization direction. Lateral variations of the fast polarization direction between the outer-rise and seaward regions are described in "Discussion" section.

\section{Methods}

\section{Po waves from OBS observation}

Two ocean bottom seismometers (OBSs) data sets were used: one from active seismic surveys (Fujie et al. 2013) and the other from passive seismic surveys (Obana et al.

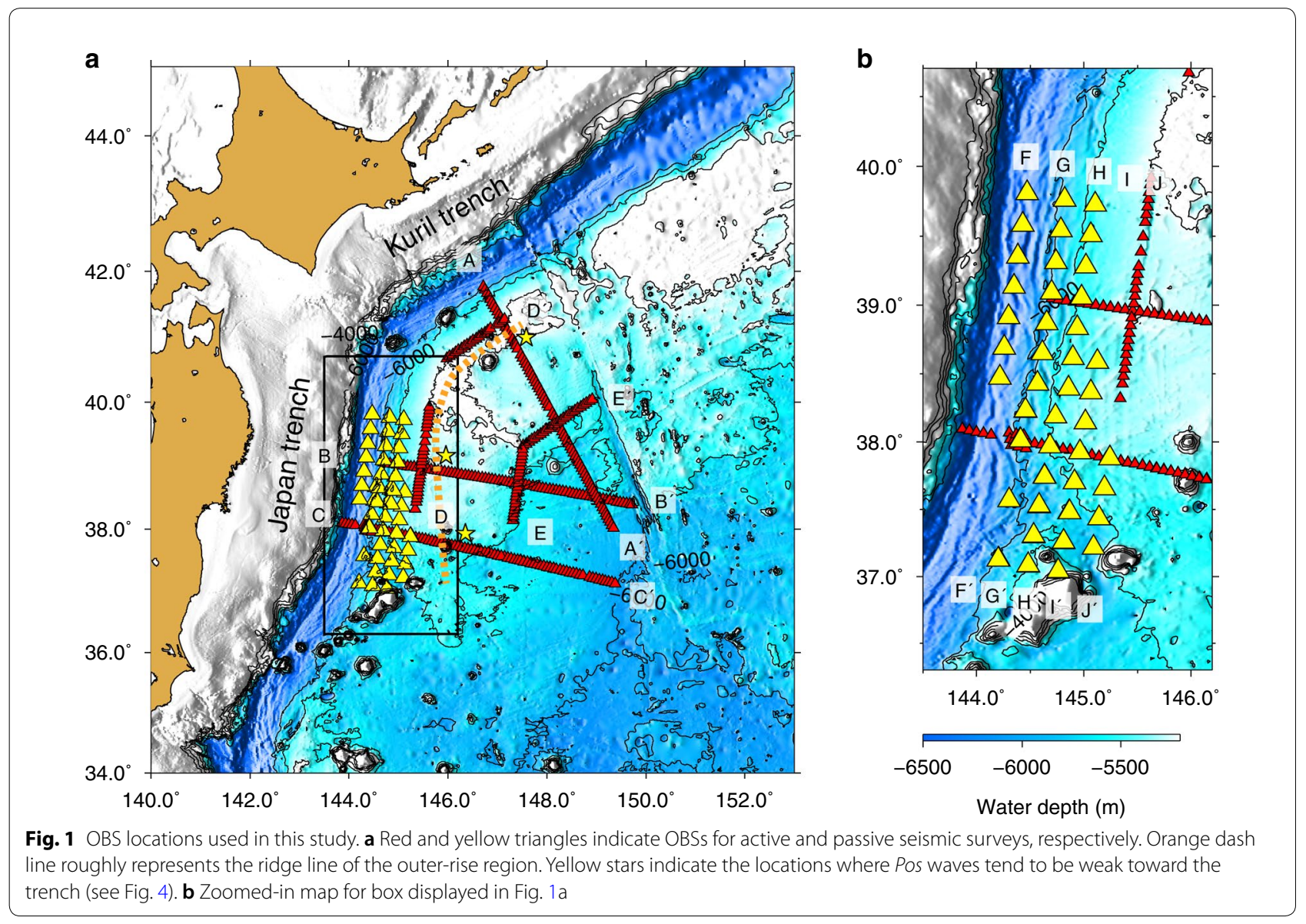


a

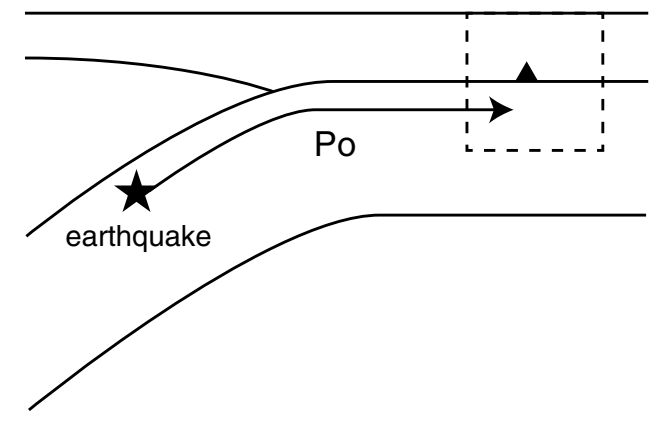

b

Sea water

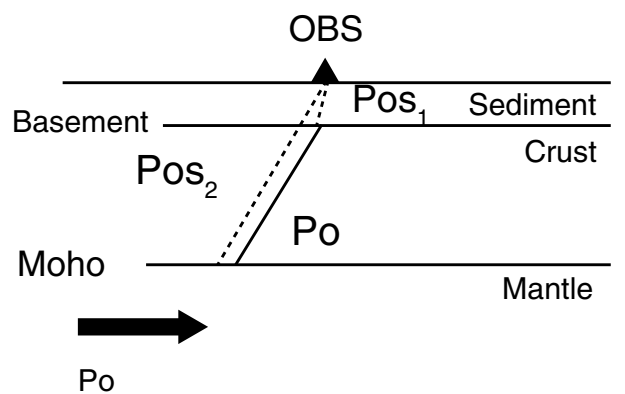

Fig. 2 Schematic of $P O$ and Pos waves observed at an OBS. a Po waves propagated in the oceanic mantle from an earthquake. $\mathbf{b}$ Pos waves were generated at the basement and oceanic Moho beneath an OBS

2012, 2013, 2014, 2018), in which three-component, short-period $(4.5 \mathrm{~Hz})$ sensors were deployed in the northwestern part of the Pacific Plate. The first set consisted of linear arrays with station spacings of $\sim 6 \mathrm{~km}$ (lines from $A-A^{\prime}$ to $E-E^{\prime}$ in Fig. 1) and had shorter observation periods (58 days for line $\mathrm{A}-\mathrm{A}^{\prime}, 22$ days for line $\mathrm{B}-\mathrm{B}^{\prime}, 40$ days for line $\mathrm{C}-\mathrm{C}^{\prime}$, and 21 days for lines $\mathrm{D}-\mathrm{D}^{\prime}$ and $\mathrm{E}-\mathrm{E}^{\prime}$ ). Po waves were collected from these data sets in time series where airgun shot signals were not recorded. In the second data set, planar OBS arrays were deployed with station spacings of $25-30 \mathrm{~km}$ from lines from $\mathrm{F}-\mathrm{F}^{\prime}$ to $\mathrm{J}-\mathrm{J}^{\prime}$ (Fig. 1). The latter data set was acquired by passive seismic surveys over four periods. The OBS array locations were shifted to overlap each other, and the total observation period was 497 days $(66+104+253+74)$. More than 350 OBS locations were used in the two data sets.

The horizontal orientation of each OBS in the active seismic surveys was determined using air gun shot signals (see Tonegawa et al. 2015). When the orientation could not be determined due to low signal-to-noise ratios $(S / N)$, this study used $T$ waves excited by earthquakes occurring in subduction zones between Mariana and Kamchatka, with magnitudes of 4.5-6.0 and focal depths shallower than $50 \mathrm{~km}$ to estimate the horizontal orientations of OBSs (see Tonegawa et al. 2016). The backazimuth (BAZ) range covered at most $220^{\circ}$. The horizontal orientations of OBSs used in passive seismic surveys were estimated using $T$ waves. As $\pi$ ambiguities exist in the orientations estimated by both techniques, the seismic phase polarities could not be identified in this study.

Po waves excited by earthquakes (magnitudes of 4.5-6.5) occurring at any depth in the subduction zones between Mariana and $180^{\circ} \mathrm{E}$ (east of Kamchatka) were collected from continuous OBS observation records (Additional file 1: Fig. S1). Po waves were manually selected to remove direct $P$ arrival contamination; in the cases of earthquakes that occur above subducting slabs (hanging wall sides) or with short propagation paths between the hypocenter and OBS, Po waves are not sufficiently developed within the oceanic plate. To ensure sufficient scattering within the mantle, thereby removing contamination by direct $P$ arrivals, earthquake signals with a straight line greater than $300 \mathrm{~km}$ between the hypocenter and the OBS were used.

\section{Extraction of Pos waves}

The normalized cross-spectra were used, calculated as

$$
\begin{aligned}
& R(\omega)=\frac{z^{*}(\omega) \cdot r(\omega)}{|z(\omega)|^{2}}, \\
& T(\omega)=\frac{z^{*}(\omega) \cdot t(\omega)}{|z(\omega)|^{2}},
\end{aligned}
$$

where $z(\omega), r(\omega)$, and $t(\omega)$ represent the vertical, radial, and transverse components of Po coda seismograms in the frequency domain, respectively, and asterisks (*) indicate the complex conjugates. To preserve the relative amplitudes of $R(\omega)$ and $T(\omega)$, the normalization was performed using a single component, $z(\omega)$. Equations (1) and (2) are equivalent to the descriptions of radial and transverse receiver functions in the frequency domain (Langston 1979; Ammon 1991). Applying the inverse Fourier transform to Eqs. (1) and (2), the radial- and transverse-normalized cross-correlation functions (RCF and TCF, respectively) were obtained.

A Gaussian-shaped bandpass filter of $2-6 \mathrm{~Hz}$ was applied to calculate Eqs. (1) and (2), and time windows of -2 to $6 \mathrm{~s}$ and from -2 to $18 \mathrm{~s}$ were used for the vertical 
and horizontal components, respectively, from handpicked $P o$ arrival times. The shorter time window of the vertical component was determined to avoid water reverberation contamination of the Po wave (Pow) and allow the first portion of $P o$ waves to be used; Fig. 3a shows the $P o$ waves at $0-2 \mathrm{~s}(2-6 \mathrm{~Hz})$ of an earthquake aligned as a function of epicentral distance with a reduced velocity of $8 \mathrm{~km} / \mathrm{s}$ alongside the Pow waves at 8-10 s. The RCF and TCF amplitudes exceed one because of the shorter time window in the vertical component; however, their relative amplitudes are preserved. Figure $3 \mathrm{~b}$ displays the
Pos waves at 2-4 s $(2-6 \mathrm{~Hz})$, during which the first peak corresponding to Pos waves converted at the top of the basement $\left.\left(P_{0}\right)_{1}\right)$. Clear Pos waves were obtained in the RCFs at 1.5-2.5 s lag time (Fig. 3c). In the Northwestern Pacific, the typical marine sediment $V p, V p / V s$, and thickness are $1.6 \mathrm{~km} / \mathrm{s}, 8$ (Fujie et al. 2013; Tonegawa et al. 2015), and <0.4 km (e.g., Fujiwara et al. 2007; Nakamura et al. 2013), respectively, resulting in a differential travel time of $1.75 \mathrm{~s}$ between vertically propagating $P$ and $S$ waves. This agrees well with the observed lag times of $\operatorname{Pos}_{1}$. Later phases were also observed at $2.0-3.0 \mathrm{~s}$ lag
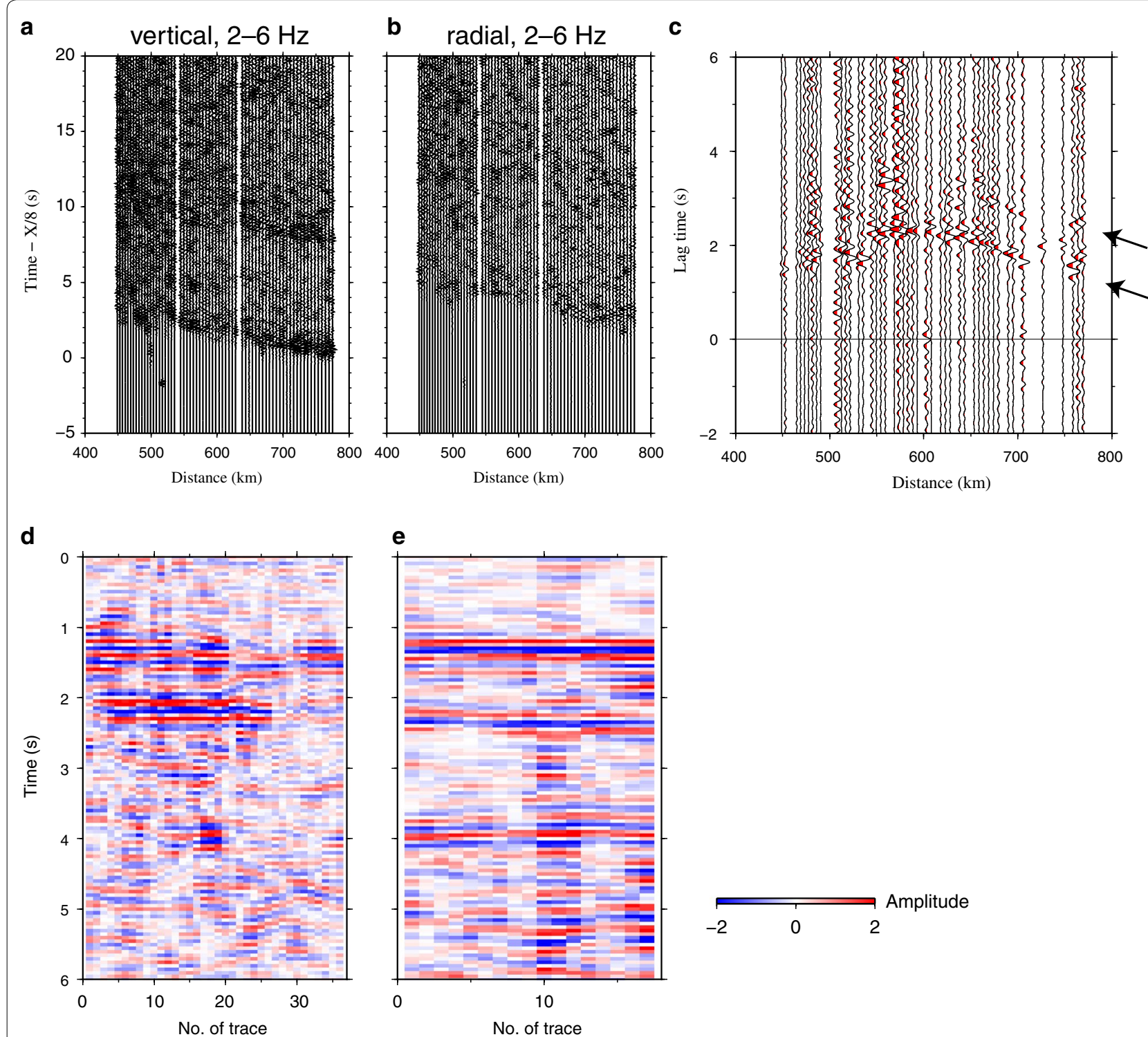

Fig. 3 Waveform examples for Pos wave retrieval calculations. Bandpassed waveforms in the a vertical and $\mathbf{b}$ radial components at 2-6 Hz for an event (Additional file 1: Fig. S1) observed at OBSs along line A-A' (Fig. 1). c RCFs using waveforms in $\mathbf{a}, \mathbf{b}$ at 2-6 Hz. Two arrows correspond to Pos waves. $\mathbf{d}$ Examples of RCFs for multiple events observed at a single OBS from passive seismic surveys. e The same as $\mathbf{d}$, but at another OBS from an active seismic survey 
times, corresponding to Pos waves converted from the oceanic Moho. When a strong Pos wave was detected with a delay time of approximately $1 \mathrm{~s}$ after $P_{0 s}$, it was defined as a Pos wave converted from the oceanic Moho $\left(\operatorname{Pos}_{2}\right)$. Delay times were determined using a velocity model $(\mathrm{Vp}=6.27 \mathrm{~km} / \mathrm{s}, \mathrm{Vs}=3.49 \mathrm{~km} / \mathrm{s})$ and an oceanic crust thickness of $7 \mathrm{~km}$ (White et al. 1992), resulting in a differential travel time of $0.89 \mathrm{~s}$ between the vertically propagating $P$ and $S$ waves.

Furthermore, the averaged $\operatorname{Pos}_{1}$ and $\operatorname{Pos}_{2}$ amplitudes are displayed for each OBS. For each RCF trace, the maximum $\operatorname{Pos}_{1}$ and $\operatorname{Pos}_{2}$ amplitudes were measured within a time window of $0.6 \mathrm{~s}$ from handpicked arrival times of those waves. The averaged $\operatorname{Pos}_{1}$ and $P_{0} s_{2}$ values at each OBS are displayed to investigate the lateral variations in their amplitudes.

\section{Estimation of anisotropy}

We apply a traditional cross-correlation approach (e.g., Ando et al. 1983; Fukao 1984) for estimating the splitting parameters (the fast polarization direction and delay time) of the marine sediment layer and oceanic (igneous) crust and count the cumulative number of both parameters in three regions: two outer-rise regions and a seaward region. Both parameters were obtained at OBSs located in each region and plotted in rose diagrams and histograms, respectively. This allowed us to use splitting information at OBSs where clear Pos waves were observed, but the number of available records was minimal due to the short observation periods. Time windows of $0.6 \mathrm{~s}$ were used from handpicked $\mathrm{Pos}_{1}$ and $\mathrm{Pos}_{2}$ arrival times. The delay time search ranges of both layers were within $0.15 \mathrm{~s}$, as determined by typical time delays at each layer and region. For each trace, the fast polarization direction and delay time of the marine sediment layer were estimated using $\operatorname{Pos}_{1}$ with a $t$ test error estimation (e.g., Kuo et al. 1994; Chang et al. 2009; Giannopoulos et al. 2015). If $C$ (cross-correlation coefficient) $>0.9, \Delta t$ (delay time) $\geq 0.03 \mathrm{~s}$, and $\Delta t$ error $<0.03 \mathrm{~s}$, the anisotropic effect of the sediment layer was removed from $\mathrm{Pos}_{2}$ (Oda 2011) under the assumption the $P_{0} s_{1}$ and $P_{0} s_{2}$ emerging in each trace have similar incidence angles of $S$ waves within the marine sediment and suffer similar splitting effects. The anisotropic structure of the oceanic crust was estimated using the corrected $\mathrm{Pos}_{2}$. When $C>0.9$ and $\Delta t<0.03 \mathrm{~s}$, the anisotropic structure of the oceanic crust was also estimated using the uncorrected $\mathrm{Pos}_{2}$. Because signal-to-noise ratios of $\mathrm{Pos}_{2}$ were small compared with those of $P_{0 s_{1}}$, the acceptance criterion was lowered to $C>0.8$. Additional criteria were set for the Pos amplitude: (1) Pos arrival times can be handpicked, and (2) the $S / N$ of Pos waves is greater than 2, in which $S / N$ is defined as the ratio of the root-mean-square (RMS) amplitudes of
Pos waves of $0.6 \mathrm{~s}$ over the noise records of -2 to $0 \mathrm{~s}$ in the NCF lag time.

Additional file 1: Figure S2 demonstrates two-layer anisotropic structure estimations from a RCF-TCF pair observed at one OBS. Crosses and dash lines in Additional file 1: Fig. S2b correspond with splitting parameter measurements with uncertainties from the $t$ test. The determined delay times and slow (negative delay time) polarization directions were $-0.03 \mathrm{~s}$ and $-63^{\circ}$ from the radial direction at the sediment layer (Additional file 1: Fig. S2b) and $-0.1 \mathrm{~s}$ and $2^{\circ}$ at the crustal layer (Additional file 1: Fig. S2d). Splitting parameters could be estimated within errors of $\pm 0.02 \mathrm{~s}$ and $\pm 20^{\circ}$, and linear particle motions could be obtained in the corrected Pos waveforms (Additional file 1: Fig. S2c and e).

\section{Results}

Observations of Pos waves from the basement and Moho

Figures 4, 5, and 6 show the observed RCFs and TCFs along lines from $\mathrm{A}-\mathrm{A}^{\prime}$ to $\mathrm{E}-\mathrm{E}^{\prime}$ and $\mathrm{F}-\mathrm{F}^{\prime}$ to $\mathrm{J}-\mathrm{J}^{\prime}$, respectively. Each box along the lines corresponds to a suite of RCFs/TCFs observed at one OBS. The waveform polarities are unity in each box, but have an ambiguity of $\pi$ in the horizontal orientation of each OBS. The blank boxes in Fig. 4 indicate OBSs where the RCFs and TCFs were not available, as no information was available for the OBS horizontal orientation or Po and Pos wave arrival times due to low $S / N$. The blank boxes in Fig. 6 represent the OBSs described above or were placed to adjust relative OBS locations along the $\mathrm{F}-\mathrm{F}^{\prime}$ to $\mathrm{J}-\mathrm{J}^{\prime}$ lines.

$\operatorname{Pos}_{1}$ waves were clearly extracted at lag times of $0.5-$ $2.0 \mathrm{~s}$ from most of the survey region (Fig. $4 \mathrm{a}-\mathrm{e}$, Additional file 1: Fig. S3a). Exceptions are observed in the northwestern portion of line $\mathrm{A}-\mathrm{A}^{\prime}$ (light-blue star and bottom arrow in Fig. 4a) and the western parts of lines $\mathrm{B}-\mathrm{B}^{\prime}$ and $\mathrm{C}-\mathrm{C}^{\prime}$ (light-blue stars and bottom arrows in Fig. 4b, c) where the $\operatorname{Pos}_{1}$ amplitudes tended to weaken with proximity to the trench. The feature in lateral variation of $\mathrm{Pos}_{2}$ amplitude was similar but weaker to those of $P o s_{1}$. When Fig. 4a is compared to Fig. 2 in Fujie et al. (2013), the lateral variations in Pos amplitudes obtained in this study were in good agreement with the active survey results in spite of the reflectivity clearly seen in the active survey.

Since the RCF/TCFs available from lines $F-F^{\prime}$ to $\mathrm{J}-\mathrm{J}^{\prime}$ were much higher than those from lines $\mathrm{A}-\mathrm{A}^{\prime}$ to E- $E^{\prime}$, this study investigated lateral variations in Pos wave appearances near the Japan Trench. The RCFs in Fig. 6a-e show Pos waves observed at OBSs deployed around the western parts of lines $\mathrm{B}-\mathrm{B}^{\prime}$ and $\mathrm{C}-\mathrm{C}^{\prime}$. The $\operatorname{Pos}_{1}$ amplitudes for each OBS fluctuated on a local scale, allowing identification at some OBSs but not others (Additional file 1: Fig. S3a). $\mathrm{Pos}_{2}$ amplitudes were 


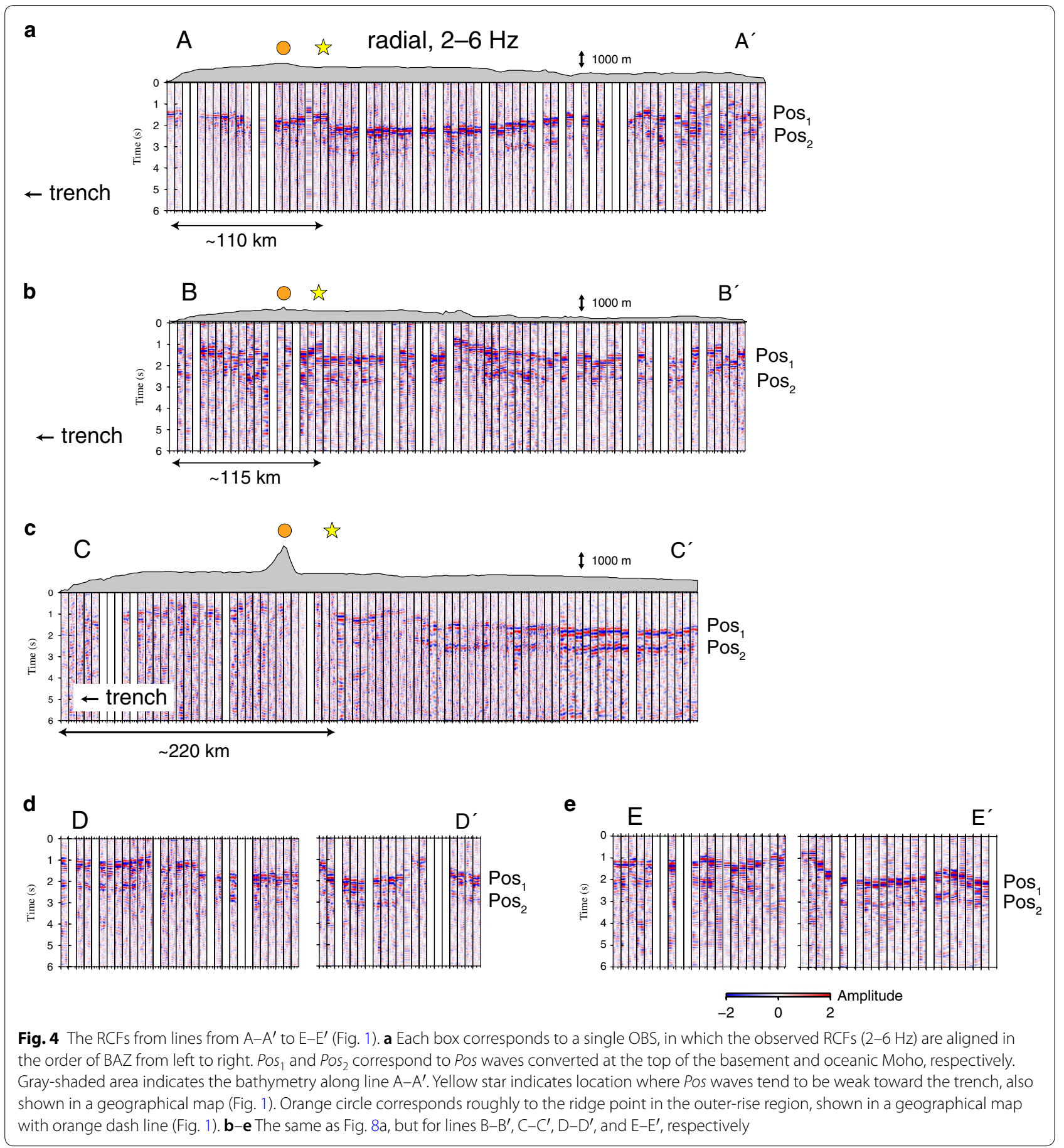

observed at three OBSs along line $\mathrm{J}-\mathrm{J}^{\prime}$ and scattered at OBSs along lines $\mathrm{G}-\mathrm{G}^{\prime}, \mathrm{H}-\mathrm{H}^{\prime}$, and $\mathrm{I}-\mathrm{I}^{\prime}$. At OBSs in line F-F', close to the Japan Trench (Fig. 1), the $P^{\prime} s_{1}$ amplitudes were significantly weaker, and the $\mathrm{Pos}_{2}$ amplitudes could not be identified.

\section{Shear wave anisotropy at the sediment and crust}

TCFs are shown along all lines (Figs. 5, 6f-j), from which $\mathrm{Pos}_{1}$ and $\mathrm{Pos}_{2}$ can be identified at most and some OBSs, respectively. These observations indicate that shear wave anisotropy was present at the sediment layer across the entire survey region and possibly at the oceanic crust 


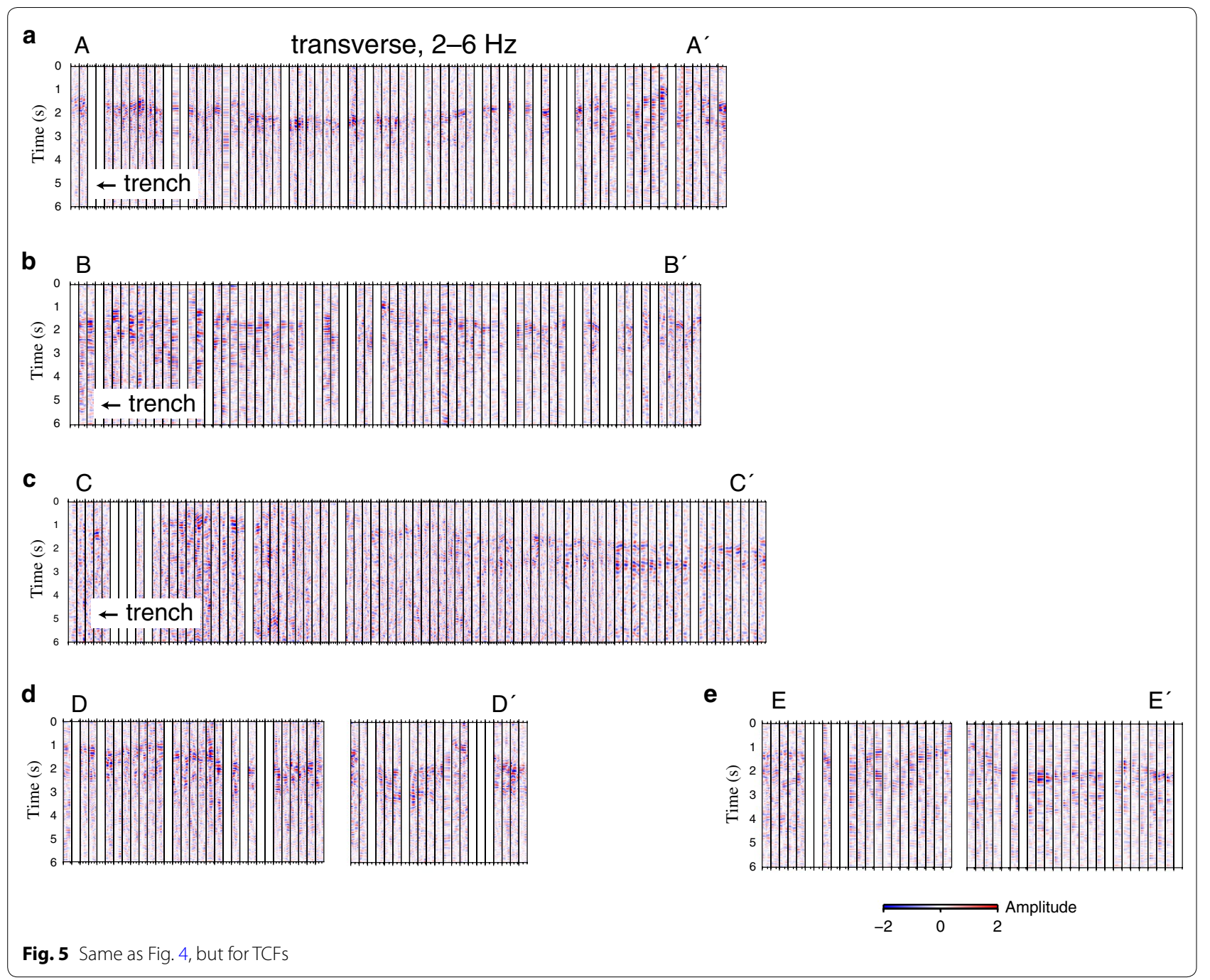

in sporadic regions. Three regions $\mathrm{K}-\mathrm{M}$ (Fig. 7) were selected based on TCF amplitude and tectonic setting: two outer-rise regions and one seaward region for regionally averaged splitting parameters. As shown in Fig. 7, the fast polarization directions at OBSs near the trench were estimated to be the trench-parallel in the regions $\mathrm{K}$ and L, consistent with Tonegawa et al. (2013, 2015), whereas the NNW-SSE-trending directions were estimated for OBSs in the region $\mathrm{M}$. Although the splitting parameters estimated for the oceanic crust were less than those of the sediment layer, similar patterns and degrees of the shear wave anisotropy to sediment could be obtained at the oceanic crust (Additional file 1: Fig. S4).

\section{Discussion}

Lateral variations in Pos wave amplitudes near the trench $\mathrm{Pos}_{1}$ and $\mathrm{Pos}_{2}$ amplitudes weakened as they approached the trench along $\mathrm{A}-\mathrm{A}^{\prime}, \mathrm{B}-\mathrm{B}^{\prime}$, and $\mathrm{C}-\mathrm{C}^{\prime}$, and their appearance changed starting slightly east of the ridge line (orange circles in Fig. $4 \mathrm{a}-\mathrm{c}$, orange line in Fig. 1) in the outer-rise region (yellow stars in Figs. 1, 4a-c). Possible reasons for this absence of waves include (1) structural variations in the seafloor, basement, and oceanic Moho topography or seismic velocity anomalies in the outer-rise to trench region (Fig. 8), and (2) noise levels at OBSs near the trench are larger than those in the seaward region.

Structural changes occurred between the outer-rise and trench regions because many normal faults develop at the uppermost oceanic plate due to the horizontal extension along the trench-normal direction associated with plate bending (Ranero et al. 2003; Ranero and Sallarès, 2004; Grevemeyer et al. 2007; Fujie et al. 2013). This has the potential to induce seafloor, basement, and oceanic Moho deformations. If $P o$ waves enter such undulated interfaces, converted $\mathrm{Pos}_{1}$ and $\mathrm{Pos}_{2}$ amplitudes 
a

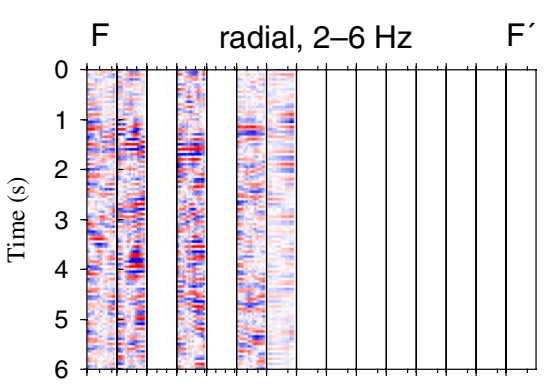

b

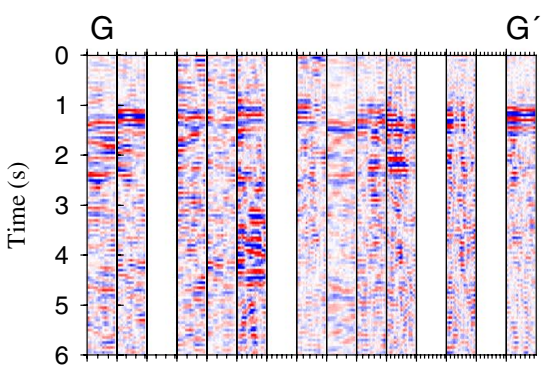

C

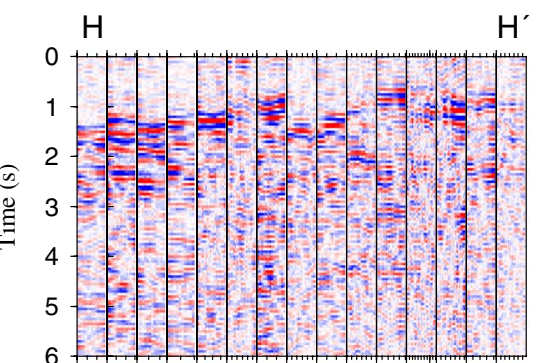

d

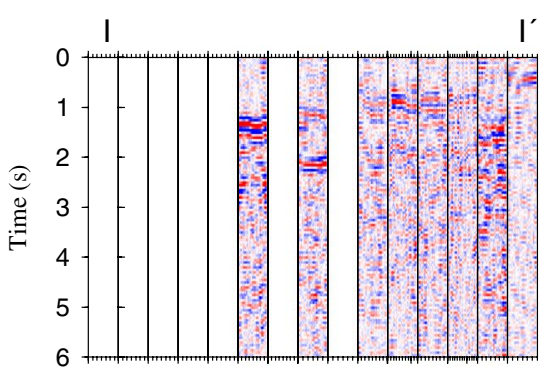

e

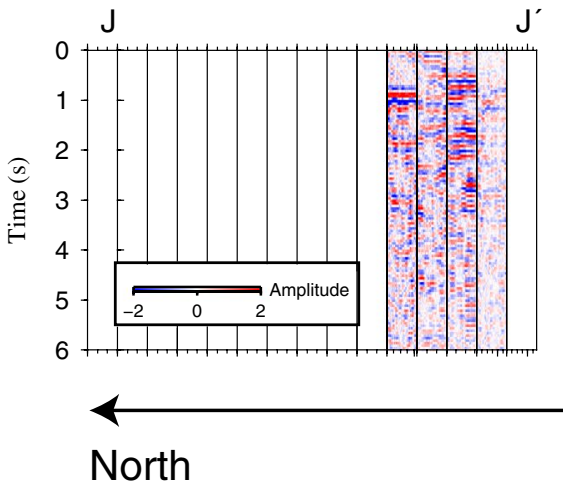

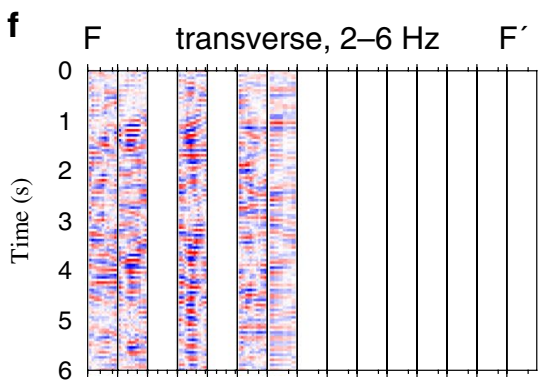

g $\mathrm{G} \quad \mathrm{G}^{\prime}$

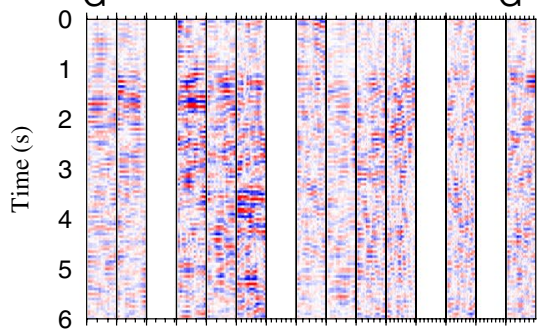

h

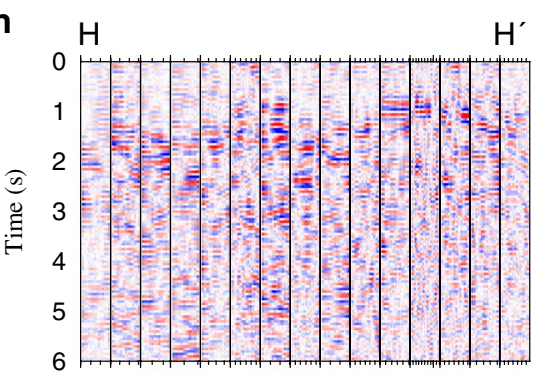

i

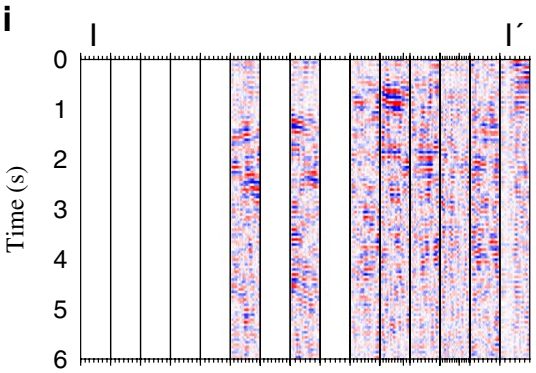

j
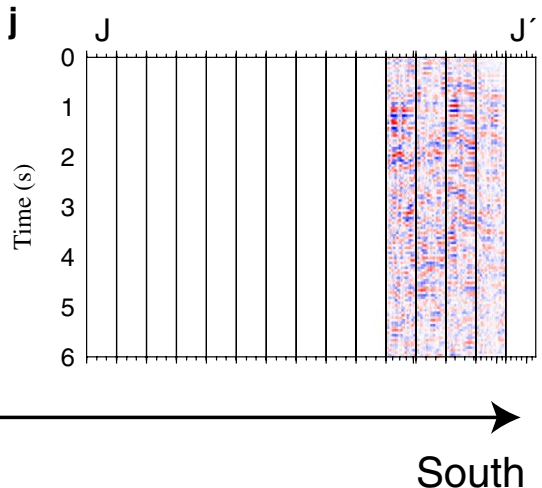

个 응

ত্তে

Fig. 6 Same as Fig. 4, but for the RCFs and TCFs from lines from F-F' to J-J' (Fig. 1) 


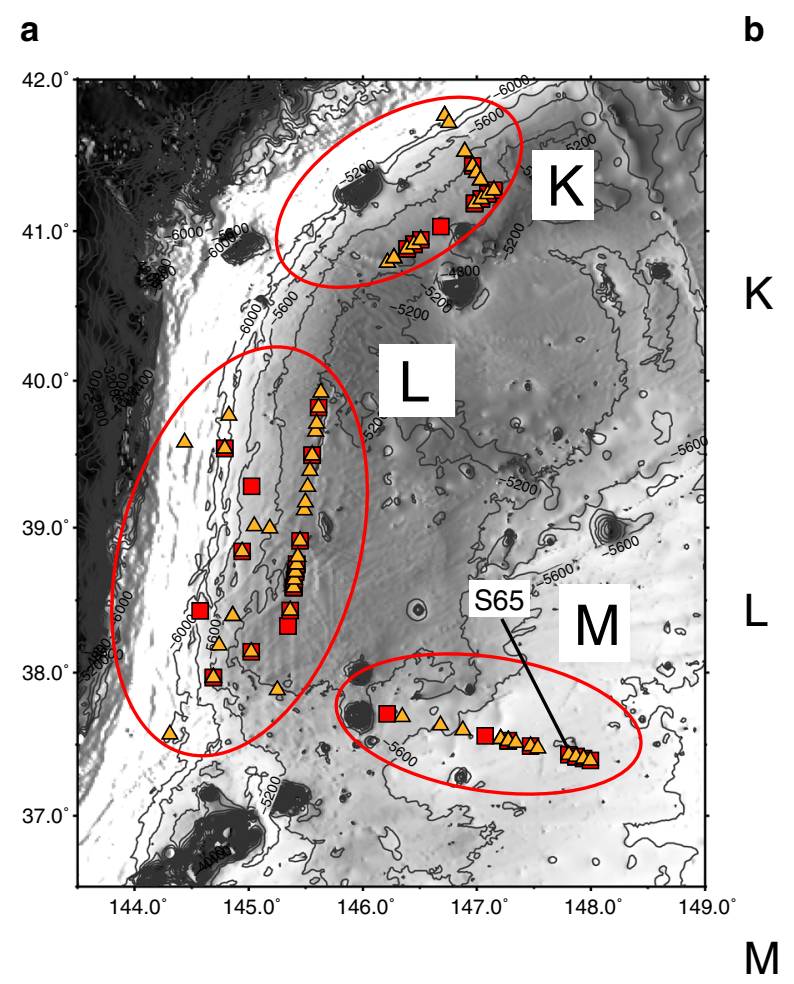

b

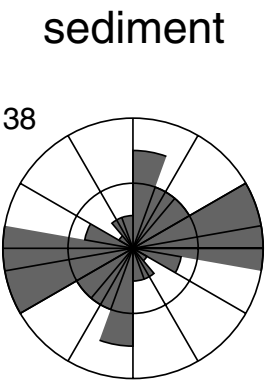

\section{crust}
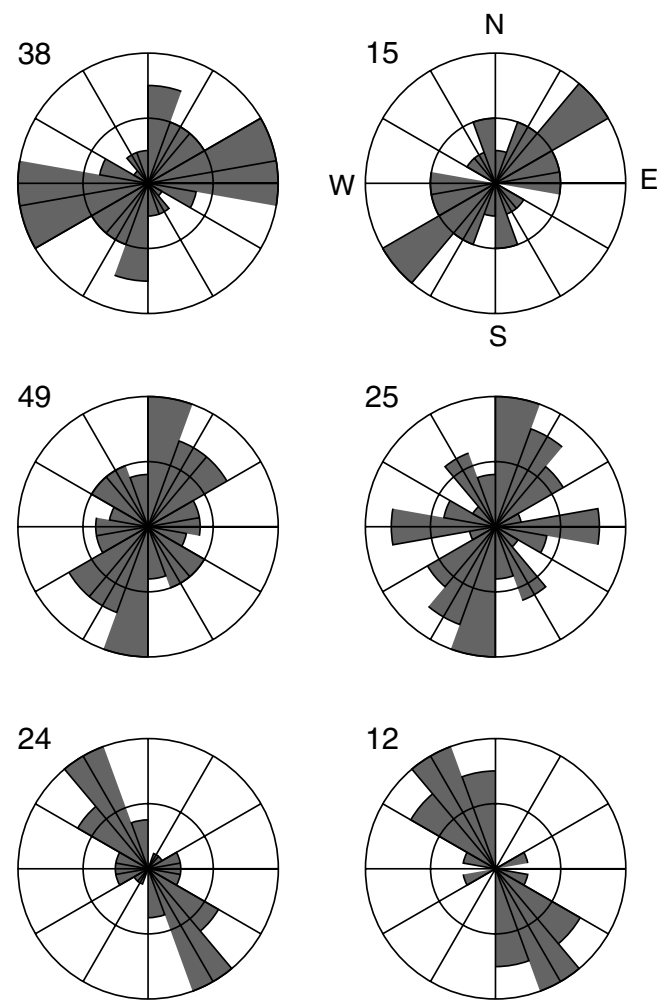

Fig. 7 Fast polarization direction results. a Geographical map for three regions, K, L, and M, indicated by ellipsoids, and OBSs used for estimating splitting parameters of sediment (orange triangles) and igneous crust (red squares). S65 indicates the OBS used in Additional file 1: Fig. S2. b Rose diagrams of the fast polarization direction for regions $\mathrm{K}-\mathrm{M}$ (row) and sediment and crustal layers (column). Numbers at the top left indicate the used Pos waves counted at OBSs within each region

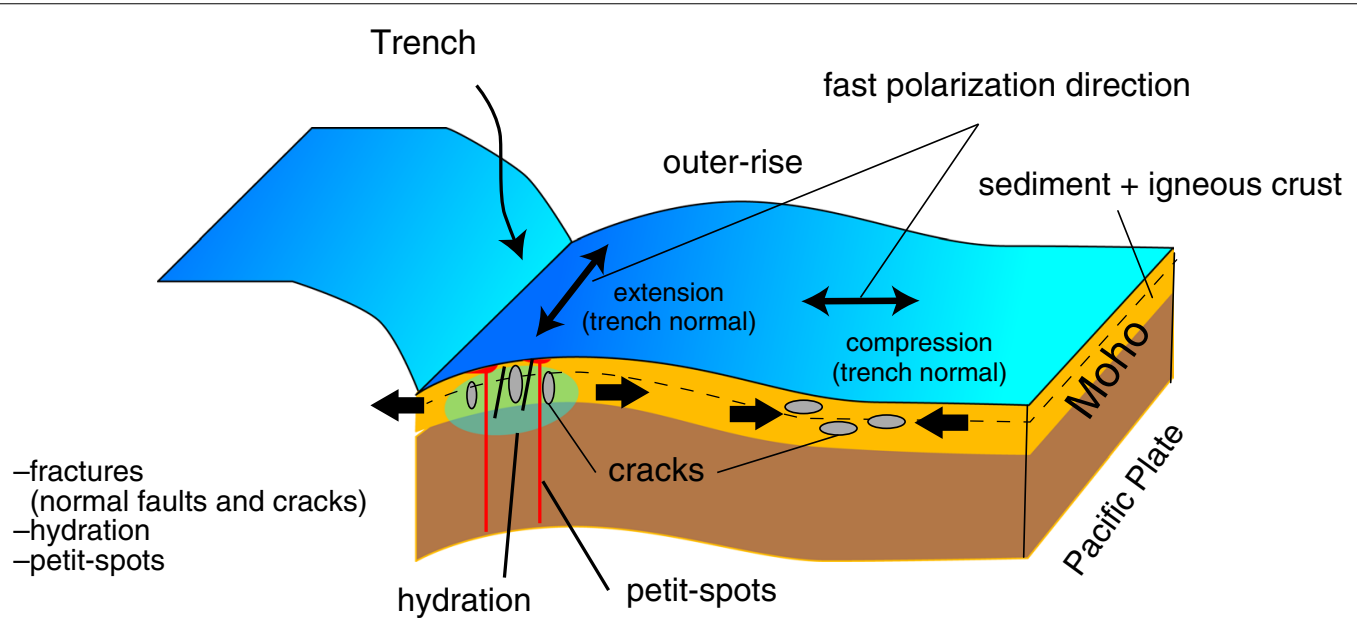

Fig. 8 Schematic for our interpretation of Pos wave appearances and fast polarization direction patterns 
would be weakened by ineffective conversion or/and raypath bending. As their travel times also vary at each OBS as a function of BAZ, the coherence of Pos waves may be reduced in the aligned time-domain RCFs. Additionally, seismic velocity reductions at shallower parts of oceanic plates have been revealed by active seismic surveys (Ranero et al. 2003; Ranero and Sallarès 2004; Grevemeyer et al. 2007; Fujie et al. 2013; Shillington et al. 2015). These can be explained by hydration at the crust and mantle through fractures due to the plate bending. If the seismic velocity contrast at the basement and Moho in this region was decreased by velocity reduction degrees at the sediment, igneous crust, and mantle, converted Pos amplitudes would be weakened. These structural factors may alter the appearance of the Pos waves along the $\mathrm{A}-\mathrm{A}^{\prime}$ and $\mathrm{B}-\mathrm{B}^{\prime}$ lines as well as across the northern part of the passive survey area (Figs. 6, 8).

For the line $\mathrm{C}-\mathrm{C}^{\prime}$ and the southern part of the passive survey area, an additional factor contributed to the absence of Pos waves: Many petit spots have been reported by previous studies along the western part of line $\mathrm{C}-\mathrm{C}^{\prime}$ (e.g., Hirano 2010). Petit spots are submarine volcanos formed on the oceanic plate, providing an outlet for alkali magma ascending from the asthenosphere (Hirano et al. 2006, 2010; Machida et al. 2015). The formation of these volcanoes, alongside their conduits and magma chambers, induces fractures in the oceanic lithosphere. In the case of high volcanic activities, the basement and oceanic Moho could also be highly deformed or broken: Hence, converted $P s_{1}$ and Pos $_{2}$ amplitudes would be weakened as in the case of fault-induced deformations of the basement and Moho. Detailed investigations of the structural variations in this region are expected to be performed in future research using depthdependent profiles from active seismic surveys.

To confirm the aforementioned point (2) contributing to Pos wave absences, noise levels were calculated for each OBS site. RMS amplitudes with a time window of -2 to $0 \mathrm{~s}$ in lag time in the RCF were estimated for noise levels. Additional file 1: Figure S3c shows a geographical map of the estimated noise levels at each OBS site, indicating noise levels increase slightly near the Japan Trench but decrease slightly near the Kuril Trench relative to seaward OBSs. Although the $\operatorname{Pos}_{1}$ was identified at most of OBSs near the Japan Trench, the $\mathrm{Pos}_{2}$ was identified at only a few OBSs. These $\operatorname{Pos}_{2}$ absences may be caused by weak $\mathrm{Pos}_{2}$ amplitudes obscured by the relatively high noise levels near the Japan Trench.

\section{Shear wave anisotropy associated with plate bending}

The results of this study revealed fast polarization directions were oriented parallel to the trench from the outerrise to trench region, but NNW-SSE-trending direction in the seaward region. The magnetic lineation across the entire survey region in this study is oriented NE-SW (normal to the direction of line A-A') (Nakanishi 2011). If the fractures and cracks formed at the spreading center during oceanic plate formation were preserved, the fast polarization would be estimated in the NE-SW direction. The present results, which contradict this expectation, thus indicate other mechanisms for creating anisotropic structure are present within the sediment across all surveyed regions and crust in spatially sporadic regions. An active seismic survey shows no significant $P$ wave velocity difference in the crust around the intersection between line $\mathrm{A}-\mathrm{A}^{\prime}$ and the northeastern segment of line E-E' (Kodaira et al. 2014). Weak and spotted anisotropic structures obtained in this study may be linked to the small azimuthal differences in $P$ wave velocity.

Possible anisotropy creation mechanisms include (1) aligned fractures (cracks and normal faults) associated with a stress field (anisotropy for the sediment and crust), (2) aligned topography at the seafloor (anisotropy for the sediment), and (3) anisotropic minerals (particularly clay for the sediment anisotropy). Because it is difficult to explain the observed patterns of the fast polarization direction in the regions $\mathrm{K}-\mathrm{M}$ using mechanism (3), mechanisms (1) and (2) are considered in the subsequent paragraphs. Here, because the marine sediments in the Northwestern Pacific have a high porosity (80\%, Kanazawa et al. 2001) and slow $V s(0.2 \mathrm{~km} / \mathrm{s}$, Tonegawa et al. 2013) in which the solid and fluid phases become continuous (bi-connected), systematic water flow channeling may occur under stress fields, inducing anisotropic seismic velocities in an effective medium. This text considered such pore channeling as cracks in the sediment.

It is suggested that current cracks were created by the stress fields associated with plate bending. As the oceanic plate surface curves upward in the outer-rise region, horizontal extensions in the trench-normal direction dominate at the uppermost oceanic plate, and hence trench-parallel cracks and normal faults are created. Under stress field near the trench, a preferred topography orientation (such as horst and graben) also developed at the seafloor in a trench-parallel direction (Nakanishi 2011). Because the aligned topography direction is similar to that of cracks and normal faults beneath the seafloor, deviations in splitting measurements from such effects would be small in the fast polarization direction and minor in delay times.

Conversely, horizontal compression is expected to dominate in the seaward region, indicating a plate flexure transition zone is present between the unbending seaward and bending outer-rise regions (Fig. 8). In this study, the fast polarization directions at the sediment and crust in the region $M$ were oriented in the 
NNW-SSE direction. It appears that this direction is not trench-normal, but corresponds to the unbending plate, associated with the bathymetry because the water depth increases moving further seaward (to SSE). Moreover, on aligned topography, because $\operatorname{Pos}_{1}$ and $\mathrm{Pos}_{2}$ were clearly seen at similar lag times at OBSs in the region $\mathrm{M}$, it is considered that the topography of the seafloor, basement, and Moho is simple and less significant aligned features on the seafloor. This may indicate that cracks are created due to horizontal compression associated with the plate flexure in this region. In order to investigate this in details, it is expected to perform seismic exploration surveys around this area or/and examine other plate-unbending areas.

\section{Conclusion}

Pos waves were retrieved from Po wave coda observed at OBSs deployed across the Northwestern Pacific. These Pos waves, converted from the basement and oceanic Moho, could be identified throughout the region, except in areas proximal to the trench. These weakened or absent Pos waves near the trench were caused by normal faults and hydration at the uppermost oceanic plate. Additionally, the volcanic activities of petit spots associated with plate flexure induced heterogeneous structures in shallow depths, thereby reducing Pos converted amplitudes. Fast polarization directions near the trench were oriented parallel to the trench, which differ from the pattern in the seaward region, corresponding to normal faults and cracks created by plate bending. Such patterns can be seen from the ridge of the outer-rise region, but may be emphasized near the trench where aligned (horst and graben) topography is developed.

\section{Additional file}

Additional file 1.Supplementary materials of the used data for Pos wave retrieval and shear wave anisotropy measurements.

\footnotetext{
Abbreviations

OBS: ocean bottom seismometer; RCF/TCF: radial/transverse cross-correlation function; Pos: Po-to-s; BAZ: backazimuth; S/N: signal-to-noise ratio; RMS: root-mean-square.

\section{Authors' contributions}

TT performed data processing and prepared the first version of manuscript. $\mathrm{KO}, \mathrm{GF}$, and SK designed seismic surveys and participated in data processing and contributed to the interpretations. All authors read and approved the final manuscript.
}

\section{Acknowledgements}

Maps and plots are created by the Generic Mapping Tools (GMT) (Wessel and Smith 1991).

\section{Competing interests}

The authors declare that they have no competing interest.

\section{Availability of data and materials}

The data that support the findings of this study are available upon request from the corresponding author.

\section{Funding}

This work is supported by a Research Fellowship of the Japan Society for the Promotion of Science (JSPS) for Grants-in-Aid for Young Scientists (B), Number 15K17753, KAKENHI Grants-in-Aid for Scientific Research (S), Number JP15H05718, and KAKENHI Grants-in-Aid for Scientific Research (B), Number JP16H04045.

\section{Publisher's Note}

Springer Nature remains neutral with regard to jurisdictional claims in published maps and institutional affiliations.

Received: 27 December 2017 Accepted: 20 June 2018

Published online: 03 July 2018

\section{References}

Ammon CJ (1991) The isolation of receiver effects from teleseismic P waveforms. Bull Seismol Soc Am 81(6):2504-2510

Ando M, Ishikawa Y, Yamazaki F (1983) Shear wave polarization anisotropy in the upper mantle beneath Honshu, Japan. J Geophys Res 88:5850-5864

Bécel A, Shillington DJ, Nedimović MR, Webb SC, Kuehn H (2015) Origin of dipping structures in fast-spreading oceanic lower crust offshore Alaska imaged by multichannel seismic data. Earth Planet Sci Lett 424(15):26-37

Brillon C, Cassidy JF, Dosso SE (2013) Onshore/offshore structure of the Juan de Fuca Plate in northern Cascadia from Bayesian receiver function inversion. Bull Seismol Soc Am 103(5):2914-2920. https://doi. org/10.1785/0120120310

Chang ETY, Liang WT, Tsai YB (2009) Seismic shear wave splitting in upper crust characterized by Taiwan tectonic convergence. Geophys J Int 177:1256-1264

Eberhart-Phillips D, Reyners M, Faccenda M, Naliboff J (2013) Along-strike variation in subducting plate seismicity and mantle wedge attenuation related to fluid release beneath the North Island, New Zealand. Phys Earth Planet Inter 225:12-27

Faccenda M, Gerya TV, Burlini L (2009) Deep slab hydration induced by bending-related variations in tectonic pressure. Nat Geosci 2:790-793. https://doi.org/10.1038/NGEO0656

Fujie G, Kodaira S, Yamashita M, Sato T, Takahashi T, Takahashi N (2013) Systematic changes in the incoming plate structure at the Kuril trench. Geophys Res Lett 40:88-93. https://doi.org/10.1029/2012GL054340

Fujie G, Kodaira S, Sato T, Takahashi T (2016) Along-trench variations in the seismic structure of the incoming Pacific plate at the outer rise of the northern Japan Trench. Geophys Res Lett 43:666-673. https://doi. org/10.1002/2015GL067363

Fujiwara T, Hirano N, Abe N, Takizawa K (2007) Subsurface structure of the "petit-spot" volcanoes on the northwestern Pacific Plate. Geophys Res Lett 34:L13305. https://doi.org/10.1029/GL030439

Fukao Y (1984) Evidence from core-reflected shear waves for anisotropy in the Earth's mantle. Nature 309:695-698

Giannopoulos D, Sokos E, Konstantinou Kl, Tselentis G (2015) Shear wave splitting and $\mathrm{Vp} / \mathrm{Ns}$ variation before and after the Efpalio earthquake sequence, western Gulf of Corinth, Greece. Geophys J Int 200:1436-1448

Grevemeyer I, Ranero CR, Flueh ER, Kläschen D, Bialas J (2007) Passive and active seismological study of bending-related faulting and mantle serpentinization at the Middle America trench. Earth Planet Sci Lett 258:528-542

Hacker BR, Peacock SM, Abers GA, Holloway SD (2003) Subduction factory 2. Are intermediate-depth earthquakes in subducting slabs linked to metamorphic dehydration reactions? J Geophys Res 108:2030. https:// doi.org/10.1029/2001JB001129

Hirano N (2010) Petit-spot volcanism: a new type of volcanic zone discovered near a trench. Geochem J 45:157-167 
Hirano N, Takahashi E, Yamamoto J, Abe N, Ingle SP, Kaneoka I, Kimura J, Hirata T, Ishii T, Ogawa Y, Machida S, Suyehiro K (2006) Volcanism in response to plate flexure. Science 313:1426-1428

Kanazawa T, Sager WW, Escutia C et al (2001) Proceedings of ODP, initial reports, vol 191. Ocean Drilling Program, College Station, TX. https://doi. org/10.2973/odp.proc.ir.191.2001

Kennett BLN, Furumura T (2013) High-frequency Po/So waves in the oceanic lithosphere: I-long-distance propagation. Geophys J Int 195:1862-1877. https://doi.org/10.1093/gji/ggt344

Kita S, Okada T, Nakajima J, Matsuzawa T, Hasegawa A (2006) Existence of a seismic belt in the upper plane of the double seismic zone extending in the along-arc direction at depths of 70-100 km beneath NE Japan. Geophys Res Lett 33:L24310. https://doi.org/10.1029/2006GL028239

Kodaira S, Fujie G, Yamashita M, Sato T, Takahashi T, Takahashi N (2014) Seismological evidence of mantle flow driving plate motions at a palaeo-spreading centre. Nat Geosci 7:371-375. https://doi.org/10.1038/NGEO2121

Kuo BY, Chen CC, Shin TC (1994) SplitS waveforms observed in northern Taiwan: implications for crustal anisotropy. Geophys Res Lett 21:1491-1494

Langston CA (1979) Structure under Mount Rainier, Washington, inferred from teleseismic body waves. J Geophys Res 84:4749-4762

Machida S, Hirano N, Sumino H, Hirata T, Yoneda S, Kato Y (2015) Petit-spot geology reveals melts in upper-most asthenosphere dragged by lithosphere. Earth Planet Sci Lett 426:267-279

Nakamura Y, Kodaira S, Miura S, Regalla C, Takahashi N (2013) High-resolution seismic imaging in the Japan Trench axis area off Miyagi, northeastern Japan. Geophys Res Lett 40:1713-1718. https://doi.org/10.1002/grl.50364

Nakanishi M (2011) Bending-related topographic structures of the subducting plate in the northwestern Pacific Ocean. In: Dilek Y, Pirajno F, Windley B (eds) Modern approaches in solid earth sciences, vol 8. Springer, Dordrecht. https://doi.org/10.1007/978-90-481-8885-7_1

Obana K, Fujie G, Takahashi T, Yamamoto Y, Nakamura Y, Kodaira S, Takahashi N, Kaneda Y, Shinohara M (2012) Normal-faulting earthquakes beneath the outer slope of the Japan Trench after the 2011 Tohoku earthquake: implications for the stress regime in the incoming Pacific plate. Geophys Res Lett 39:L00G24. https://doi.org/10.1029/2011gl050399

Obana K, Kodaira S, Shinohara M, Hino R, Uehira K, Shiobara H, Nakahigashi K, Yamada T, Sugioka H, Ito A, Nakamura Y, Miura S, No T, Takahashi N (2013) Aftershocks near the updip end of the 2011 Tohoku-Oki earthquake. Earth Planet Sci Lett 382:111-116. https://doi.org/10.1016/j. epsl.2013.09.007

Obana K, Kodaira S, Nakamura Y, Sato T, Fujie G, Takahashi T, Yamamoto Y (2014) Aftershocks of the December 7, 2012 intraplate doublet neat the Japan Trench axis. Earth Planets Space 66:24. https://doi. org/10.1186/1880-5981-66-24

Obana K, Nakamura Y, Fujie G, Kodaira S, Kaiho Y, Yamamoto Y, Miura S (2018) Seismicity in the source areas of the 1896 and 1933 Sanriku earthquakes and implications for large near-trench earthquake faults. Geophys J Int 212:2061-2072. https://doi.org/10.1093/gji/gg×532
Oda H (2011) Stripping analysis of Ps-converted wave polarization anisotropy. Bull Seismol Soc Am 101(6):2810-2818

Ranero CR, Sallarès V (2004) Geophysical evidence for hydration of the crust and mantle of the Nazca plate during bending at the north Chile trench. Geology 32(7):549-552

Ranero CR, Morga JP, McIntosh K, Reichert C (2003) Bending-related faulting and mantle serpentinization at the Middle America trench. Nature 425:367-373

Shelly DR, Beroza GC, Ide S, Nakamura S (2006) Low-frequency earthquakes in Shikoku, Japan, and their relationship to episodic tremor and slip. Nature 442:188-191

Shillington DJ, Bécel A, Nedimović MR, Kuehn H, Webb SC, Abers GA, Keranen KM, Li J, Delescluse M, Mattei-Salicrup GA (2015) Link between plate fabric, hydration and subduction zone seismicity in Alaska. Nat Geosc 8:961-964. https://doi.org/10.1038/NGEO2586

Shinohara M, Fukano T, Kanazawa T, Araki E, Suyehiro K, Mochizuki M, Nakahigashi K, Yamada T, Mochizuki K (2008) Upper mantle and crustal seismic structure beneath the northwestern Pacific Basin using a seafloor borehole broadband seismometer and ocean bottom seismometers. Phys Earth Planet Inter 170:95-106

Shito A, Suetsugu D, Furumura T, Sugioka H, Ito A (2013) Small-scale heterogeneities in the oceanic lithosphere inferred from guided waves. Geophys Res Lett 40:1708-1712. https://doi.org/10.1002/grl.50330

Shito A, Suetsugu D, Furumura T (2015) Evolution of the oceanic lithosphere inferred from Po/So waves traveling in the Philippine Sea Plate. J Geophys Res 7:5238-5248. https://doi.org/10.1002/2014JB011814

Tonegawa T, Fukao Y, Nishida K, Sugioka H, Ito A (2013) A temporal change of shear wave anisotropy within the marine sedimentary layer associated with the 2011 Tohoku-Oki earthquake. J Geophys Res. https://doi. org/10.1002/jgrb.50074

Tonegawa T, Fukao Y, Fujie G, Takemura S, Takahashi T, Kodaira S (2015) Geographical distribution of shear wave anisotropy within marine sediments in the northwestern Pacific. Prog Earth Planet Sci 2:27. https://doi. org/10.1186/s40645-015-0057-2

Tonegawa T, Obana K, Yamamoto Y, Kodaira S, Wang K, Riedel M, Kao H, Spence G (2016) Fracture alignments in marine sediments off Vancouver Island from Ps splitting analysis. Bull Seismol Soc Am 107:387-402. https ://doi.org/10.1785/0120160090

Wessel P, Smith WHF (1991) Free software helps map and display data. EOS Trans AGU 72:441

White RS, McKenzie D, O'Nions K (1992) Oceanic crustal thickness from seismic measurements and rare earth element inversions. J Geophys Res 97:19683-19715

Yamasaki T, Seno T (2003) Double seismic zone and dehydration embrittlement of the subducting slab. J Geophys Res 108:2212. https://doi. org/10.1029/2002JB001918

\section{Submit your manuscript to a SpringerOpen ${ }^{\odot}$ journal and benefit from:}

- Convenient online submission

- Rigorous peer review

- Open access: articles freely available online

- High visibility within the field

- Retaining the copyright to your article

Submit your next manuscript at springeropen.com 